\title{
Gestión municipal desde la perspectiva de las organizaciones inteligentes y ámbito jurídico ${ }^{\star}$
}

\section{Municipal management from the perspective of intelligent organizations and the legal field}

\author{
MPA. Jennifer Isabel Arroyo Chacón $n^{* *}$
}

\begin{abstract}
* Investigación desarrollada dentro curso Diseño de las organizaciones del Doctorado en Gestión Pública y Ciencias Empresariales del Instituto Centroamericano de Administración Pública (ICAP).

** (E) PhD. Gestión Pública y Ciencias Empresariales, Instituto Centroamericano de Administración Pública (ICAP).info@profesorajenniferarroyo.com
\end{abstract}

Cómo citar: Aroyo, J.I. (2016). Gestión municipal desde la perspectiva de las organizaciones inteligentes y ámbito jurídico. Inciso, 18 (2):127-141.

\section{Resumen}

El presente texto pretende realizar una propuesta para mejorar la gestión del sector municipal desde la perspectiva de las organizaciones inteligentes y el marco jurídico aplicable a partir del análisis de la problemática que presenta este sector. Para ello comienza analizando la figura de la descentralización en el ordenamiento jurídico costarricense y procede a realizar una descripción detallada de la problemática del sector a partir de los resultados del Índice de Gestión Municipal, considerando las debilidades de la gestión presupuestaria y analizando la gestión tributaria municipal. A partir de ésta contextualización procede a realizar propuestas desde el ámbito del diseño de las organizaciones como desde la perspectiva jurídica. Desde el enfoque del diseño de las organizaciones se recalca la necesidad de Líderes transformacionales, la necesidad de la caórdica en el ámbito municipal, plantea la aplicación de la adhocracia en proyectos municipales y la implementación del enfoque sistémico en el ámbito municipal, todo ello con el fin de arribar al modelo de la nueva gerencia pública. Desde el marco jurídico se analiza la necesidad de aplicar una interpretación sistémica del ordenamiento jurídico vigente y la aprobación de un Código Tributario Municipal y reforma a las leyes que crean tributos especiales municipales. Concluye con la imperiosa necesidad de transformar romper los paradigmas imperantes en la gestión municipal y avanzar del modelo burocrático al diseño de las organizaciones inteligentes modernas.

Palabras clave: Sector descentralizado, sector municipal, organizaciones inteligentes y liderazgo transformacional.

\begin{abstract}
This text presents a proposal to improve the municipal sector management, from the perspective of intelligent organizations and the applicable legal framework, parting from an analysis to the problem undergone by this sector. For such purpose, it starts by analyzing the figure of decentralization in the Costa Rican legal system, and then it presents a detailed description of the sector problem, parting from results of the Municipal Management index, considering weaknesses of budget management, and analyzing the municipal tax management. Parting from this contextualization, it presents proposals from the field of organizations design, and from the legal perspective.

From the approach of organizations design it is highlighted the need for transforming Leaders, the need for the caordic in the municipal field; it states the application of adhocracy on municipal projects, and implementation of systemic approach in the municipal field, everything in order to reach the model of new public management. From the legal framework, it is analyzed the need of making a systemic interpretation of the legal system in effect, and approval of a Municipal Tax Code, and amendment of laws which create municipal special taxes. It concludes with the urgent need of transforming and breaking the prevailing paradigms of municipal management, and advancing from the bureaucratic model to design of modern intelligent organizations.
\end{abstract}

Keywords: Decentralized sector, municipal sector, intelligent organizations, and transforming leadership. . 


\section{Introducción}

Al sector municipal se le define como el gobierno local, la primera cara del Estado frente al ciudadano y por ende debería ser la organización mejor gestionada, dado que conoce con detalle las necesidades particulares de cada cantón y posee una relación más directa con el ciudadano que el Gobierno Central; no obstante, la realidad demuestra una situación totalmente contraria.

En el caso costarricense pese a que constitucionalmente se le define como el sector descentralizado territorial con autonomía administrativa, política y financiera y potestades de autorganización para el cumplimiento de sus fines posee una gran dependencia del Gobierno Central, y debilidades de gestión importantes.

En el presente texto se pretenden analizar las áreas de mejora comunes desde la perspectiva administrativa bajo un enfoque de diseño de las organizaciones y desde el ámbito jurídico vigente; haciendo énfasis en aquellos aspectos jurídicos y de gestión que deben ser corregidos para obtener un sector municipal bajo los preceptos de la Nueva Gerencia Pública.

\section{De la figura de la descentralización en el ordenamiento jurídico costarricense}

\section{El concepto de descentralización}

Para comprender la figura de la descentralización se debe iniciar señalando que el Estado es el Ente Público Mayor, ello significa que únicamente existe un Estado; ahora bien, para efectos administrativos -de distribución y cumplimiento de funciones- se subdivide en dos grandes sectores: centralizado y descentralizado.

Para efectos de este documento interesa enfocarnos en el sector descentralizado que surge cuando el Estado transfiere parte de sus competencias a alguno de sus órganos para que éstos las ejecuten, esta descentralización puede ser institucional o territorial. El magistrado Ernesto Jinesta (2002) define descentralización administrativa como la transferencia intersubjetiva y definitiva de la titularidad y el ejercicio de competencias específicas y exclusivas.
La descentralización también se puede entender (Jinesta, 2009) como un proceso mediante el cual se transfieren competencias y poder político desde el gobierno central a instancias del Estado cercanas a la población, dotadas de recursos financieros e independencia administrativa, así como de legitimidad propia, a fin de que, con la participación ciudadana y en su beneficio, se mejore la producción de bienes y servicios. La Sala Constitucional Costarricense ha señalado como notas características del ente descentralizado: la personalidad jurídica, el patrimonio propio, la pluripersonalidad directiva (Junta Directiva), la especialidad orgánica y el contralor en vía administrativa y jurisdiccional.

En Costa Rica se cuenta con el sector público descentralizado institucional que se conforma por el conjunto de entes públicos "menores" (descentralizados precisamente respecto del Estado, que es el ente público mayor) entendida esta descentralización (Jinesta, 2009) como una transferencia de las responsabilidades de planificación, administración, obtención y asignación de recursos desde el gobierno central a: unidades locales de los ministerios u organismos del gobierno central; unidades o ámbitos subordinados al gobierno; instituciones o corporaciones públicas semi-autónomas; instituciones regionales $\mathrm{o}$ funcionales que cubren una zona determinada; y organizaciones del sector privado o voluntario, y el sector público descentralizado territorial, que corresponde a las corporaciones municipalidades.

La descentralización implica autonomía, el ordenamiento jurídico costarricense reconoce tres grados de autonomía, que van desde el más básico hasta la autonomía plena.

\section{Grados de autonomía}

\section{Autonomía Política o de Gobierno Primer grado de autonomía (administrativa o mínima)}

Facultad de un ente público menor de realizar sus competencias y atribuciones legales, por sí mismo, sin estar sujeto a otro ente. Potestad de auto-administrarse y disponer de sus recursos de la forma que mejor lo considere para alcanzar los fines establecidos. 
Segundo grado de autonomía (política, de gobierno o media)

Se refiere la posibilidad de un ente público de autodirigirse o autogobernarse políticamente: fijarse sus propios lineamientos, objetivos, fines o metas, a través de una potestad de programación o de planificación, sin que el ente público mayor pueda imponerselos, mediante el ejercicio de la tutela administrativa o su potestad de dirección intersubjetiva en la materia de su competencia.

\section{Tercer grado de autonomía (organizativa o plena)}

Potestad de auto-organizarse aún en ausencia de ley, esto es, con exclusión de toda potestad legislativa. Autonomía plena, ni siquiera por vía de ley se les puede someter a potestades de planificación o programación, dirección y coordinación.

Una de las causales principales de la problemática presentada con el sector descentralizado es el paradigma mediante el cual la sociedad costarricense ha entendido la descentralización; pues se entiende únicamente como una transferencia de competencias del Gobierno Central de tal manera que, aunque constitucionalmente se garantiza la autonomía, por ende, no hay un verdadero empowerment para la toma de decisiones.

En otras palabras, se transfieren las competencias, pero no la capacidad de tomar decisiones libremente, un ejemplo de esta limitante se explicará más adelante en el ámbito presupuestario, dado que muchas instituciones municipales dependen de transferencias de gobierno central o bien, empréstitos para subsistir; no obstante, cuando llegan esos recursos su destino ya se encuentra condicionado a los parámetros dados por quién los transfieren.

Este paradigma bajo el cual se ha comprendido la descentralización le impide actuar verdaderamente de forma autónoma, por lo que en el fondo existe una concentración del poder de parte del Gobierno Central. Max Weber planteó en el ámbito de la gestión administrativa la teoría del poder y la dificultad de quién lo posee de cederlo; de tal manera que, aunque en bases teóricas el gobierno central transfiere sus competencias al sector descentralizado territorial, éste pretende seguir concentrando el poder; en consecuencia, esta descentralización no opera como una verdadera independencia, sino que se buscan mecanismos que le permitan mantener este sector bajo su subordinación, causándole múltiples debilidades.

De tal manera, que se debe empezar por cuestionar si la descentralización debe seguir operando como lo ha hecho hasta la fecha -como el simple traslado de funciones y competencias-; y plantear la necesidad de emigrar a una descentralización que implique una verdadera autonomía del ente descentralizado, otorgándolo de capacidades suficientes para la toma de decisiones libres y responsables.

\section{Elsectormunicipal como sector descentralizado}

La municipalidad es un ente territorial menor creada constitucionalmente, una para cada cantón, siendo responsable de la administración general de sus intereses y servicios. En el caso costarricense se le garantiza autonomía plena dada constitucionalmente y se constituyen como el sector público descentralizado territorial, según el artículo 168 de la Ley No 7794 denominada Código Municipal de Costa Rica, que a la letra dice:

ARTÍCULO 168.- Para los efectos de la Administración Pública, el territorio nacional se divide en provincias; éstas en cantones y los cantones en distritos. La ley podrá establecer distribuciones especiales.

La Asamblea Legislativa podrá decretar, observando los trámites de reforma parcial a esta Constitución, la creación de nuevas provincias, siempre que el proyecto respectivo fuera aprobado de previo en un plebiscito que la Asamblea ordenará celebrar en la provincia o provincias que soporten la desmembración.

La creación de nuevos cantones requiere ser aprobada por la Asamblea Legislativa mediante votación no menor de los dos tercios del total de sus miembros. (Asamblea Legislativa, 1998)

Por lo que se puede definir como un ente público menor, siendo una persona jurídica estatal, con patrimonio propio y personalidad, y capacidad jurídica plenas para ejecutar todo tipo de actos y contratos necesarios para cumplir sus fines. En su 
configuración se destacan tres actores relevantes que son:

a) El alcalde: Uno por cantón, no es subordinado al Consejo Municipal poseen el mismo nivel de jerarquía.

b) Concejo Municipal: Integrado por regidores

c) Síndicos: Uno por distrito

La figura de la municipalidad es de gran relevancia pues se le conoce como el "gobierno local", es por excelencia el primer prestador de servicio público a la ciudadanía, conoce las necesidades y condiciones de vida locales, la problemática comunal de manera directa, y forma la primera opinión del ciudadano sobre el sector público; por ende, se requiere que sean órganos eficientes, organizaciones fractuales (Henric-Coll, 2014) son aquellas organizaciones que en lugar de luchar contra el entorno se ajustan a él y poseen capacidad de adaptación, dado que están sumergidas en ambientes diversos y cambiantes; no obstante, la realidad demuestra que carecen de esta capacidad de adaptación.

El gobierno local, el primer gobierno, es quizás el más deficiente en el país -inclusive se podría afirmar que en toda Latinoamérica- prestando la mayor cantidad de servicios el gobierno central que en principio posee un margen de actuación nacional y más distante del ciudadano.

Se debe señalar que dentro de la complejidad que reviste este sector se encuentra la diversidad de condiciones en que están inmersas las municipalidades, dado que las condiciones exógenas y endógenas de cada cantón son diferentes, y en algunos casos diametralmente opuestas, influyendo en el rendimiento de cada municipalidad; de tal forma, que las comparaciones y afirmaciones genéricas poseen esa limitante; no obstante, para efectos de éste estudio resulta necesario estudiar a las municipalidades en su conjunto partiendo de sus similitudes y omitiendo sus particularidades.

Bajo este enfoque se estudiará en el siguiente acápite las principales problemáticas coincidentes en este sector municipal costarricense.

\section{Descripción de la problemática del sector municipal}

\section{Resultados del Î́ndice de Gestión Municipal}

La Contraloría General de la República (2015) en el ejercicio de su deber de velar por el correcto uso de los fondos públicos elabora anualmente una evaluación de las instituciones que integran el sector municipal en el país y apartir de los insumos obtenidos emite el Índice de Gestión Municipal -en adelante IGM-, documento en el cual se reflejan las mejoras que ha tenido el sector, pero también las áreas debiles y mayores dificultades presentadas por estos órganos.

El IGM evalúa 61 indicadores organizados en cinco ejes estratégicos que se enlistan a continuación:

\section{Desarrollo y gestión institucional}

- Gestión Financiera

- Control Interno

- Contratación Administrativa

- Tecnologías de Informació

- Recursos Humanos

\section{Gestión de servicios}

- Gestión Vial

\section{Planificación, participación}

- Planificación

- Participación Ciudadana

- Rendición de Cuentas

\section{Gestión de desarrollo ambiental}

- Recolección de Residuos

- Depósito y Tratamiento de Residuos

- Aseo de Vías y Sitios Públicos 


\section{Gestión de servicios sociales}

- $\quad$ Parques y Obras de Ornato

- Atención de Servicios y Obras Sociales

Para la última evaluación realizada, correspondiente al año 2014 y publicada a mediados del año 2015, la calificación promedio obtenida por el sector es relativamente Los principales resultados por eje se detallan en la tabla 1. Principales resultados por eje: baja, un 59\%; no obstante, ha sufrido una mejora de $2.7 \%$ respecto a la calificación general del 2013; por lo que en términos globales se aprecia un esfuerzo municipal de cumplir con lo requerido en éstos puntos.

Las áreas de servicio de aseo de vías y sitios públicos reportaron una mejora; al contrario de la subárea de ingresos y egresos, el área de contratación administrativa y la atención de servicios y obras sociales reportaron una disminución (Contraloría General de la República, 2015).

Tabla 1. Principales resultados por eje
Este índice evidencia debilidades que afectan de forma común al sector municipal, presentan un lento avance en la materia; poseen serias dificultades para brindar servicios públicos como parques y obras de ornato, aseo de vías y sitios púbicos, depósito y tratamiento de residuos y recolección de residuos, financieramente sostenibles, producto de la tenencia de tasas desactualizadas o inexistentes $y$; en consecuencia, sin la inversión para su desarrollo.

En otras palabras, las municipalidades carecen de un enfoque orientado al servicio, permanecen dentro de una "irracionalidad" -el divorcio entre la realidad que percibe la municipalidad y la realidad del ciudadanoplanteado por Crozier y Friedberg (1990) y bajo un presunto "orden" que no es otra cosa que el desorden que destruye las bases de la gestión municipal.

Lo expuesto se une a las debilidades del sistema de control interno, dificultades para la elaboración, aprobación $y$ publicación de instrumentos de planificación, especialmente de planes reguladores. En este punto se debe considerar la teoría de las "disfunciones de la burocracia" y el "ritualismo burocrático" planteados por Merton (1995), pues aun

\begin{tabular}{|c|c|c|}
\hline Eje & Áreas problemáticas & Áreas con mejoría \\
\hline \multirow{4}{*}{ Desarrollo y Gestión I. } & Control Interno & Formulación de los planes reguladores. \\
\hline & Liquidación Presupuestaria & Cobertura de planes reguladores \\
\hline & $\begin{array}{l}\text { Incremento en las nulidades de los } \\
\text { procedimientos de contratación. }\end{array}$ & $\begin{array}{l}\text { Satisfacción de los usuarios respecto de los } \\
\text { servicios brindados. }\end{array}$ \\
\hline & $\begin{array}{l}\text { Cumplimiento de las metas trazadas en los } \\
\text { planes operativos anuales. }\end{array}$ & \\
\hline \multirow[t]{2}{*}{ Gestión Ambiental } & $\begin{array}{l}\text { Rubro con la calificación más baja durante los } \\
\text { últimos } 5 \text { años. }\end{array}$ & Sostenibilidad financiera de los servicios. \\
\hline & Sostenibilidad del servicio de aseo de vías & Inversión para desarrollo \\
\hline \multirow[t]{2}{*}{ Gestión de servicios económicos } & $\begin{array}{l}\text { Ejecución de los ingresos disponibles para } \\
\text { gestión vial. }\end{array}$ & $\begin{array}{l}\text { Procesos de planificación para la mejora de la } \\
\text { condición de la red vial cantonal. }\end{array}$ \\
\hline & Sostenibilidad y aprobación de la tasa. & \\
\hline \multirow[t]{2}{*}{ Gestión de servicios sociales } & Tasa de parques y obras de ornato & Servicio de parques \\
\hline & Ejecución de los servicios y proyectos sociales & \\
\hline
\end{tabular}

Fuente: Elaboración propia con base en el Índice de Gestión Municipal 
cuando las organizaciones municipales se caracterizan por ser burocráticas -en el sentido negativo que posee este término- carecen de procedimientos eficientes, e incluso de parámetros de control adecuados que permitan garantizar que la institución alcanzará los fines y objetivos propuestos.

La disminución en la recaudación de ingresos y los bajos porcentajes de ejecución del gasto, afectan la ejecución del gasto en servicios y de capital; la ejecución y porcentaje de recursos destinados a la prestación de servicios y obras sociales, y presupuestos participativos.

Lo expuesto es un ejemplo claro del "irrealismo" que habla Crozier cuando afirma que las organizaciones públicas viven en una realidad diferente a la "realidad"; las entidades de gobierno actúan de una manera que no se ajusta a las demandas de los ciudadanos; pues si bien, en este índice se consideró como hecho positivo la mejora en la percepción de la prestación de servicios al ciudadano local, este rubro dista mucho de obtener una buena calificación, las quejas por la inadecuada prestación del servicio son constantes y reiteradas en todo el ámbito municipal.

En síntesis, las áreas en las cuales las municipalidades costarricenses deben trabajar más son: control interno, planificación urbana, presupuesto participativo, sostenibilidad financiera y aprobación de las tasas en los servicios e inversión para su desarrollo, y ejecución del gasto previsto en servicios y obras sociales.

\section{Gestión presupuestaria municipal}

Por disposición constitucional a la Contraloría General de la República le corresponde aprobar los presupuestos de las instituciones del sector público descentralizado, el cual incluye al sector municipal.

Para el año 2016 el órgano contralor aprobó 75 presupuestos, quedando 6 instituciones sin aprobación presupuestaria en virtud de incumplimientos al ordenamiento jurídico aplicable en la formulación y aprobación presupuestaria, provocando demoras en la ejecución de los recursos, por lo que deberán regirse por el presupuesto del año anterior, situación que repercutirá negativa en el desempeño municipal de dicha localidad.
Dentro de los principales problemas identificados en la labor presupuestaria y señalados en el Informe Presupuestos Públicos (Contraloría General de la República, 2016) se destacan:

- Un sistema de administración financiera desarticulado

- Ausencia de controles mínimos en el manejo de los recursos públicos

- Ausencia de un proceso presupuestario participativo que permita a la participación ciudadana contribuir en la formulación y ejecución del presupuesto acorde con la realidad económica de cada cantón y del ayuntamiento.

- Ausencia de instrumentos de planificación y de manuales para su regulación.

- Toma de decisiones de forma inoportuno y una inadecuada rendición de cuentas.

Esta problemática se entiende por la ausencia de la visión sistémica en éstas instituciones, pues no han podido comprender que el presupuesto no es un elemento aislado de la gestión municipal o un trámite que deben realizar únicamente para presentarlo ante el órgano contralor, sino que responde a los objetivos que pretende alcanzar la municipalidad plasmados en los proyectos que integran su planificación considerando los recursos disponibles para ello.

Peter Senge (1995) en su libro La Quinta Disciplina señala que las organizaciones deben dejar de ver los árboles para empezar a ver el bosque, lo cual rompe con el paradigma imperante en el sector municipal que atiende una tarea o labor en particular perdiendo la perspectiva del impacto que la misma posee en las demás áreas de la gestión municipal.

Aunado a lo expuesto, se mantiene una preocupación por las altas tasas de morosidad en el pago de las obligaciones tributarias por parte de los contribuyentes, -ingresos corrientes- que terminan minando las finanzas municipales, por lo que debe ser una prioridad fortalecer la gestión de cobro.

Lo expuesto ha conllevado a que los órganos municipales recurran al financiamiento para sufragar la inversión 
municipal, incrementándose la importancia de este rubro con las repercusiones financieras que posee el endeudamiento, aplicando -con consecuencias poco satisfactorias- la teoría del hombre administrativo de Simon y March (1993), en donde el administrador deja de buscar la mejor solución por inclinarse a la solución satisfactoria; en este caso, ante la ausencia de recursos los órganos municipales en vez de preocuparse por mejorar la recaudación tributaria recurren como respuesta satisfactoria al empréstito, sin considerar el costo financiero que ello posee y su impacto en las finanzas futuras de la entidad.

Igualmente preocupa que pese al incremento en los prestamos como fuente de recursos económicos, también se incrementa el superávit específico con el consecuente deterioro en la prestación del servicio público, creando un paradigma contradictorio, por un lado las administraciones municipales resultan incompetentes para ejecutar sus recursos y por otro, deben recurrir a empréstitos para la prestación de servicios e inversión pública dadas las dificultades de realizar una adecuada recaudación tributaria.

Se destaca el hecho de que los gastos presupuestados para el 2016 se dirigen principalmente a financiar obligaciones ordinarias de las municipalidades; cuyo principal rubro de gasto corriente son los salarios de los servidores municipales; con poco margen para la inversión en obras municipales.

En términos generales el sector municipal denota una problemática en el manejo de sus finanzas dado que presentan: déficits presupuestarios recurrentes, financiamiento con recursos de superávits específicos, niveles elevados de morosidad, la desactualización de tasas, el endeudamiento municipal e inversiones transitorias con recursos de superávit, entre otros.

\section{La problemática de la gestión tributaria municipal}

Como se mencionó anteriormente una de las principales problemáticas de las municipalidades es la morosidad y la poca recaudación de sus ingresos tributarios, y ello tiene como génesis mismo la concepción del sistema tributario municipal imperante en el país.
Para Torrealba Navas (2014) el sistema tributario municipal presenta importantes deficiencias a la luz de los principios constitucionales de: autonomía, corresponsabilidad fiscal, suficiencia coordinación y solidaridad que regulan la coexistencia de Haciendas Públicas de distintos niveles, la estatal y la municipal en el caso costarricense.

Pese a que la Constitución Política les garantiza a las municipalidades autonomía financiera, en la práctica existe una subordinación del sector descentralizado territorial al gobierno nacional. Para lograr ésta autonomía se requiere de autonomía presupuestaria; es decir, que las municipalidades sean las que libremente decidan en qué van a gastar sus recursos; no obstante, al depender en muchos casos de recursos del gobierno central y de empréstitos con entidades financieras supranacionales éstos recursos ya se encuentran condicionados en su uso desde su origen.

Asimismo, la autonomía tributaria debe ir aparejada con el principio de corresponsabilidad fiscal: los munícipes deben participar con su propio esfuerzo fiscal para financiar sus bienes y servicios públicos, para evitar fenómenos de paternalismo. Los tributos propios y cedidos del municipio son esenciales para garantizar la suficiencia recaudatoria y deberían contener una regulación uniforme en aspectos materiales generales, procedimentales y sancionatorios, para garantizar el principio de coordinación.

Dentro del abanico de tributos municipales existentes podemos identificar como más relevantes -dado que se encuentran en todas las municipalidades y generan la mayor cantidad de ingresos tributarios- los que se enlistan en la Figura 1. Principales tributos municipales.

Pese a la existencia de éstos tributos existen deficiencias a nivel de la técnica legislativa empleada para constituirlos que repercuten de manera negativa en la capacidad de recaudación fiscal que poseen las corporaciones municipales, por las razones que se detallan en la Tabla 2. Obstáculos en la determinación de los tributos municipales: 


\section{Patentes}

\section{Espectáculos públicos}

\section{Impuesto a las construcciones}

\section{Ley de impuesto de ventas ambulantes y estacionarias}

\section{Impuesto sobre bienes inmuebles.}

Tabla 2. Obstáculos en la determinación de los tributos municipales

\begin{tabular}{ll}
\hline \multicolumn{1}{c}{ Tributos municipales } & \multicolumn{1}{c}{ Principales críticas } \\
\hline Impuesto de bienes inmuebles & $\begin{array}{l}\text { Deficiencias en la definición del hecho generador. } \\
\text { Deficiencias en la determinación del sujeto pasivo y su grado } \\
\text { de responsabilidad. } \\
\text { Ausencia de sistematización de las excepciones en un solo } \\
\text { texto legal y algunas son difíciles de administrar. } \\
\text { Carece de una regulación uniforme técnicamente correcta. } \\
\text { Peficiencias en la determinación del hecho generador -debería } \\
\text { grabarse toda la actividad lucrativa con sistemas objetivos de } \\
\text { determinación del tributo-. } \\
\text { Confusión en aspectos fundamentales del tributo: } \\
\text { estructuración de los sujetos pasivos deudores del impuesto. } \\
\text { Confusión sobre el sujeto obligado al pago del tributo. } \\
\text { Deficiencias en la determinación del hecho generador. } \\
\text { Ausencia de regulación clara respecto a las tasas municipales. } \\
\text { Criterios contradictorios emitidos por los Tribunales y la } \\
\text { Procuraduría General de la República respecto a las tasas } \\
\text { municipales. } \\
\text { Regulación escaza a nivel nacional } \\
\text { Las municipalidades carecen de regulación al respecto - } \\
\text { únicamente dos municipalidades poseen reglamentación de } \\
\text { las contribuciones especiales- }\end{array}$ \\
\hline
\end{tabular}

Fuente: Elaboración propia con base en la documentación de consulta. 
Adicionalmente, se debe reconocer la incapacidad que poseen estos órganos municipales de atender dos funciones prioritarias en el esquema tributario moderno que son: atención al contribuyente y control fiscal.

En atención al contribuyente se carece de un Digesto Tributario Municipal, falta de uniformidad de criterios técnicos y jurídicos aplicables a la solución de controversias tributarias específicas, por lo que cada estructura tributaria municipal debe construir dicha uniformidad; lo cual no siempre se logra pues existe gran cantidad de criterios contradictorios dejando en indefensión al contribuyente que no cuentan con claridad sobre cómo se resolverá su gestión, lo cual evidentemente violenta el principio de seguridad jurídica.

Incluso, muchas municipalidades carecen de Unidad Tributaria, lo cual no solo repercute negativamente en la gestión cobratoria municipal, sino que le impiden brindar asesoría al contribuyente, que no tiene claridad de a quién consultarle y muchas veces recibe respuestas contradictorias e incompletas.

En el segundo elemento: control tributario, también existen áreas de mejora, provocados por la falta de recursos técnicos y humanos capacitados en la materia -que tiende a ser muy especializada-, falta de depuración de la información y en general porque es una función que queda delegada a la de recaudación que es el eje sobre el cual las municipalidades estructuran su gestión tributaria.

El registro de contribuyentes presenta significativas variaciones dado que algunas municipalidades con mayor desarrollo tecnológico poseen sistemas informáticos para ello, y otras simplemente una hoja de Excel; imposibilitando la existencia de un registro único de contribuyentes.

Las municipalidades captan información por medio de declaraciones e información de terceros pero que no someten a verificación alguna, provocando deficiencias de control y baja calidad de los datos que poseen para el establecimiento de las cargas tributarias.

Entre otras deficiencias señaladas por la Contraloría General de la República y el reconocido tributarista
Torrealba Navas (2014) en su documento Visión General del Sistema Tributario Municipal elaborado a petición del órgano contralor.

\section{Propuesta para transformar al ente municipal en una organización inteligente}

Propuestas desde ámbito del diseño de las organizaciones

\section{Necesidad de líderes transformacionales}

Todo proceso de cambio requiere de líderes que los dirijan y en el caso de transformaciones tan relevantes como la propuesta, cambiar de organizaciones municipales burocráticas e ineficientes a organizaciones municipales inteligentes -organización que aprende-, se requiere de líderes especialmente capacitados para éstos procesos.

Enotraspalabras, serequieredelíderestransformacionales que (Peris Pichastor, 1998) son aquellos que inspiran a sus seguidores a cambiar expectativas, percepciones y motivaciones con el objetivo de trabajar hacia logros comunes, incluso con el desarrollo de una influencia idealizada (carisma) e inspiración.

El liderazgo transformacional se plantea como el tipo de liderazgo necesario del siglo actual por las constantes variaciones en el entorno; siendo por ende el líder que requiere el sector municipal; no obstante, en este punto surge una limitante que tiene que ver con la elección del Alcalde y los regidores dado que éstos casos se dan por elección popular en donde no siempre se elige al más competente.

Por lo tanto, se requiere que la ciudadanía rompa el paradigma predominante para la elección de éstos cargos, y comience a valorar las capacidades formales y cualidades blandas de los candidatos, procurando aquellos que ejercen un liderazgo transformacional, es decir, con la capacidad de liderar proceso de cambio (Gandarillas \& Briñol , 2010).

Asimismo, este liderazgo no es exclusivo de los altos cargos, sino de todos aquellos funcionarios con poder de dirección dentro de la organización, por lo que conviene capacitar a los encargados y responsables en las herramientas que van a necesitar para inspirar a sus subordinados hacia procesos de cambio para mejora de la prestación del servicio municipal. 


\section{Necesidad de la caórdica en el ámbito municipal}

Para comenzar a solucionar la problemática antes descrita, la cual no solo es abundante sino también bastante diversa pues versa sobre prácticamente todas las áreas del ámbito municipal, es necesario empezar por romper el paradigma de la descentralización que ha imperado hasta la fecha en el ideario jurídico costarricense.

Asimismo, se deben romper los paradigmas tradicionales que han moldeado las municipalidades costarricenses para formar pensamiento divergente que las mueva hacia nuevas formas de gerenciar en lo público basándose en principios de gerencia estratégica; y la mejor manera de lograrlo es implementando los principios de la caórdica.

La caórdica (Ramírez Amador, 2013) procura romper el presunto orden imperante en una entidad para generar un caos que la mueva hacia el futuro, causar un desequilibrio -en un sentido positivo del términoque las obligue a adaptarse al entorno y crear un nuevo orden, un impulso hacia la organización fractual, la cual procura adaptarse a las adversidades que la envuelven.

Esta caórdica se puede promover a través de la exigencia del respeto de los principios que integran el Open Government, como lo son la transparencia, rendición de cuentas y participación ciudadana, en donde el nuevo ciudadano posee un papel protagónico y determinante, dado que le corresponde presionar a la entidad municipal al punto tal de romper con su presunto orden.

El nuevo ciudadano y el nuevo rol que cumple el Estado, ya no como dueño de la información y de los servicios, sino como una organización al servicio y disposición de los intereses del ciudadano constituyen el detonante para hacer ver a las organizaciones municipales su irracionalidad e imperiosa necesidad de cambiar la visión y concentrarse en el ciudadano.

Promoviendo una organización inteligente, definida (Espinosa Vizcaíno, 2011) como aquella organización que aprende, que promueve el conocimiento individual de sus servidores y a su vez, el conocimiento colectivo de tal forma que se apliquen criterios de mejora continua y sistemas de control de calidad permanentes dando espacio a la innovación.

\section{Aplicación de la adhocracia en proyectos municipales}

La municipalidad en esencia fue creada para atender necesidades puntuales de las comunidades que pueden ser atendidas de diversas maneras; pese a ello, el paradigma tradicional que ha imperado ha sido el de contar con personal en planilla para realizar todas éstas funciones; lo que provoca que éstos órganos siempre posean recursos humanos limitados, pues las funciones que deben realizar son muchas y de muy diversa índole.

Esta visión posee efectos negativos en el presupuesto municipal, en donde los recursos se destinan principalmente para gastos corrientes en lugar de inversión, y dentro de los gastos corrientes la partida más relevante es remuneraciones. Recapitulando las municipalidades poseen limitaciones económicas, entre otras causas, por la inadecuada gestión de cobro de los tributos municipales, en donde los ingresos que se reciben se destinan mayoritariamente al pago de salarios, dejando un margen muy pequeño para el desarrollo de proyectos.

Para romper con esta cadena viciosa se propone implementar la adhocracia en el ámbito municipal; es decir, empezar a gestionar las labores municipales como proyectos que pueden ser atendidos por equipos interdisciplinarios y altamente competentes creados únicamente para atender un proyecto en particular y que una vez finalizado el mismo se proceda a su desintegración, con lo cual se disminuye la carga en planilla que actualmente poseen.

La adhocracia promueve la gestión por equipos de trabajo dirigidos por un líder transformacional que atenderán un proyecto en particular, y una vez terminada dicha tarea se desintegra, para darle oportunidad a la organización de formar otro equipo de trabajo con las condiciones necesarias para atender un proyecto diverso, -en donde eventualmente podría volver a recontratar a colaboradores sobresalientes-, 
sin tener que contratar a todo ese personal de forma permanente -con la dificultad que implica el prescindir de los servicios de aquellos funcionarios que resultan ineficientes-.

Cítese por ejemplo la atención de servicios y obras sociales la cual puede ser satisfecha por medio de proyectos específicos para atender a los sectores prioritarios de la comunidad que se brinde por medio de un equipo interdisciplinario de profesionales dirigidos por un líder y contratados únicamente por el plazo del proyecto.

Éstos equipos deberán contar con líderes transformacionales (Peris Pichastor, 1998) es aquel líder que provoca transformaciones en su entorno, debidamente empoderados por las municipalidades para tomar las decisiones que considere oportunas para el buen término del proyecto, sin necesidad de esperar respuesta para cada acción -con lo cual se elimina la problemática de los atrasos provocados por la lentitud de respuesta de las autoridades administrativas- y que, a su vez, sean campos de cultivo para ideas innovadores.

En consecuencia, la estructura de la municipalidad cambiaría de forma importante, pues pasaría de prestar servicios en forma directa a ser un gestor de proyectos con el personal de planta mínimo para la coordinación respectiva de éstos equipos adhocráticos.

\section{Implementación del enfoque sistémico en el ámbito municipal}

En acápites anteriores se señaló como una de las causales de la problemática municipal la ausencia del enfoque sistémico dado que éstas se caracterizan por atender las áreas de la gestión municipal de forma aislada; por ejemplo, la gestión presupuestaria considerada como una función que hay que cumplirle a la Contraloría General desconociendo el impacto determinante que ésta posee en toda la labor institucional.

Por lo que conviene aplicar los principios expuestos por Peter Senge en su libro La Quinta Disciplina (1995) para que éstos órganos integren todos los componentes que componen su actuar. Tomando en consideración los cinco elementos propuestos por Senge que se diseñan en la Figura 3. La quinta disciplina:

Figura 3. La quinta disciplina
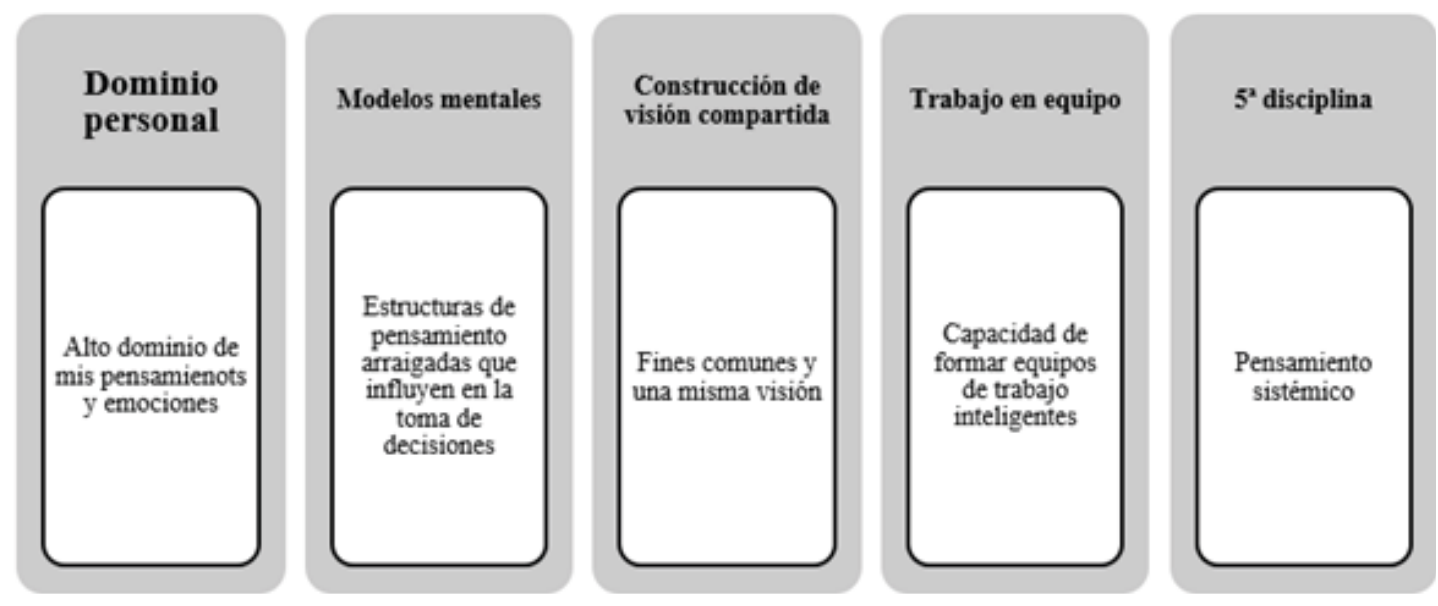

Fuente: Elaboración propia con base en el libro La quinta disciplina 
Se divide en diez aspectos: 1. Dadme una palanca y moveré el mundo, 2. Disciplinas de la organización inteligente, 3. $5^{\circ}$ disciplina: Piedra angular de la organización inteligente, 4. El arte de ver los árboles sin dejar de ver el bosque, 5. Disciplinas centrales para construir una organización con capacidad de aprendizaje, 6. Visión personal, 7. Modelos mentales, 8. Visión compartida, 9. Teoría Organizacional y 10. Nueva función para un líder.

Lo señalado implica un cambio de mentalidad en la visión de la municipalidad, un cambio de paradigma respecto a la estructura, organización y gestión municipal, que tiende a la jerarquía y modelo burocrático propuesto por Max Weber, y emigrar hacia un modelo de gestión más moderno y completo siguiendo la teoría sistémica de las organizaciones que le permitan a las autoridades nacionales y locales concebir a la municipalidad como un sistema en donde cada parte debe trabajar de forma precisa y harmónica con el resto de tal manera que todo el conjunto opere correctamente.

\section{El modelo de la nueva gerencia pública}

La Nueva Gestión Pública es el término utilizado durante las últimas decadas para promover las reformas necesarias en la gestión pública tomando como pilar los principios de eficacia, eficiencia y economía de tal forma que se pueda romper con el modelo burocrático propuesto por Max Weber en su momento, y que con el tiempo ha conllevado a la irracionalidad de las administraciones públicas, planteada por Crozier y superar las disfunciones de la burocracia señaladas por Merton tendientes a la construcción del nuevo modelo de Estado.

La Nueva Gestión Pública demanda de un Nuevo Gerente Público, en donde las habilitades personales superan las carácteristicas formales, revistiendo de vital importancia las cualidades de liderazgo, principalmente, de liderazgo transformacional.

La administración pública debe enfocarse en atraer este tipo de líderes, lo cual es sin duda un reto, principalmente para el sector municipal que posee esquemas de remuneración rígidos y tradicionales como lo es el esquema de remuneración de salario base más pluses, que en pocas ocasiones son atractivos para la clase profesional; de tal manera, que el primer reto es cuestionarse el paradigma del esquema de remuneración actual con el fin de valorar la implementación de esquemas más flexibles y competitivos, en donde la remuneración se base en el rendimiento y alcance de objetivos propuestos.

Esta metodología unida a la adhocracia explicada líneas atrás permitirían una mayor eficiencia en el uso de los recursos públicos al recibir un mayor rendimiento por cada colón invertido.

Esta propuesta está íntimamente vinculada con la Gobernanza que se define como el proceso mediante el cual los actores de una sociedad deciden sus objetivos de convivencia -fundamentales y coyunturales- y las formas de coordinarse para realizarlos: sus sentidos y su capacidad de dirección todo esto con implicaciones organizacionales, y en el cual el liderazgo ejercido por el Estado en todas sus manifestaciones resulta fundamental.

En consecuencia, todo ciudadano tiene "derecho a la buena gobernanza pública"; como un derecho de los ciudadanos a vivir en un entorno adecuado, la OCDE (2012) la define como la construcción de un mejor entorno nacional y local en el cual las personas puedan vivir, aprender y trabajar; en el que los emprendedores puedan innovar y comercializar los resultados de su creatividad; y en el que las empresas puedan invertir para generar riqueza y empleo. La buena gobernanza es la mejora de la confianza en el gobierno, en sus instituciones, en la calidad de sus servicios y decisiones, porque se perciben como algo que se hace en beneficio del interés público general.

Confianza de la ciudadanía en el gobierno local que sobre decir resulta bastante débil en la población costarricense, como resultado de las deficiencias que posee este sector y que han sido enlistadas previamente; por lo que su construcción es una labor dificil que requiere de actuaciones modernas y cambios significativos.

Procurando la construcción del Estado Inteligente - el Estado del futuro- aquel que se necesita para atender de forma satisfactoria las nuevas demandas ciudadanas, -un Estado abierto al cambio-, consiente de dicho cambio y con facilidades de adaptación, con 
imaginación creativa y la capacidad sinérgica para potenciar los recursos psicosociales de una sociedad.

\section{Propuestas desde el marco jurídico aplicable}

\section{Interpretación sistémica del ordenamiento jurídico}

Para implementar cambios en el sector público se requiere contar con una norma jurídica que lo respalde, de tal manera que con el fin de promover las propuestas de orden administrativo resulta necesario aplicar una interpretación sistémica del ordenamiento jurídico tomando como fundamento el artículo 4 del Código Municipal en concordancia con los artículos constitucionales antes citados.

La ley reitera la autonomía política, administrativa y financiera otorgada constitucionalmente y dentro de sus atribuciones enlista los instrumentos necesarios para implementar los cambios estructurales y organizativos necesarios para implementar un modelo sistémico como.

a) Dictar los reglamentos autónomos de organización y de servicio, así como cualquier otra disposición que autorice el ordenamiento jurídico.

b) Acordar sus presupuestos y ejecutarlos.

c) Aprobar las tasas, los precios y las contribuciones municipales, así como proponer los proyectos de tarifas de impuestos municipales.

d) Percibir y administrar, en su carácter de administración tributaria, los tributos y demás ingresos municipales.

e) Concertar, con personas o entidades nacionales o extranjeras, pactos, convenios o contratos necesarios para el cumplimiento de sus funciones.

f) Promover un desarrollo local participativo e inclusivo, que contemple la diversidad de las necesidades y los intereses de la población.

g) Impulsar políticas públicas locales para la promoción de los derechos y la ciudadanía de las mujeres, en favor de la igualdad y la equidad de género.
Nótese que dichas atribuciones son amplias; al igual que los incisos c) y d) del numeral 13 del Código Municipal al señalar que el Concejo Municipal posee la potestad de dictar los reglamentos de la corporación municipal por medio de los cuales organizará la prestación de los servicios que presta a la comunidad.

Ello aunado al derecho que posee todo ciudadano a la buena gobernanza y a recibir servicios de calidad, permiten que bajo una interpretación amplia e integral del ordenamiento jurídico exista autorización legal para que un líder transformacional en el ámbito municipal, implemente las modificaciones necesarias para instaurar los principios propios de las organizaciones inteligentes en la municipalidad a su cargo.

Por lo que se puede afirmar que existe capacidad legal para realizar estos cambios, sin irrespetar el principio de legalidad que rige la actuación del sector público.

\section{Código Tributario Municipal y reforma a las leyes que crean tributos especiales municipales}

Dentro de las áreas señaladas como problemáticas para el ámbito municipal se incluye la materia tributaria, la cual posee un gran impacto pues es la fuente natural de los recursos con los cuales cuentan las corporaciones municipales para ejecutar sus proyectos; no obstante, es allí donde mayores niveles evasión fiscal se presentan, provocada por su incapacidad para gestionar el cobro y agravada por un marco normativo muchas veces impreciso, contradictorio y que permite la evasión.

Derivado de ello surge la propuesta de aprobar un Código Tributario Municipal que sea distinto al Código Tributario Nacional al considerar las particularidades propias del sector, y que permita subsanar los vacíos y armonizar conceptos propios de la materia tributaria municipal.

Se requiere de un instrumento jurídico general que defina claramente el hecho generador de los tributos municipales, acabando con las interpretaciones individuales que realiza cada municipalidad al respecto; además de una regulación clara de la figura de la tasa que ha sido ampliamente discutida por la 
jurisprudencia nacional, llegando a resoluciones contradictorias que en nada contribuyen a la adecuada gestión municipal.

Igualmente, es necesario que el Código Tributario Municipal establezca un régimen sancionatorio uniforme para todo el país, actualmente cada municipalidad tiene su propio régimen sancionatorio e incluso algunas, no lo han reglamentado, lo cual impide sancionar a un contribuyente por incumplimientos tributarios. Éste régimen debe ser regulado por los mismos principios y tener reglas claras de su ejecución.

Actualmente existe un proyecto de Código Tributario Municipal, no obstante, ha sido criticado por los expertos en la materia dadas las claras deficiencias que contiene, en consecuencia, que se requiere de una propuesta correcta que venga a contribuir a la gestión tributaria nacional.

\section{Conclusiones}

Las municipalidades revisten de gran importancia para el desarrollo del país y de las comunidades, principalmente en la prestación directa de servicios al usuario por lo que se requiere de administraciones municipales eficientes y modernas. La realidad refleja que poseen grandes limitaciones e importantes áreas de mejora que le impiden prestar un servicio eficiente con los niveles de calidad que exige el ciudadano.

Lo expuesto tiene su origen en los paradigmas que tradicionalmente han orientado la gestión municipal que deben ser renovados e incluir aspectos de gestión de organizaciones modernas, como temas de liderazgo transformacional, adhocracia, organización fractual y similares tendientes a convertirse en organizaciones inteligentes.

Partiendo de la premisa de que es posible implementar modelos de gestión modernos en el sector público, y transformar a las organizaciones municipales en organizaciones inteligentes siempre que exista el interés y la voluntad de hacerlo, siendo éste el único y principal requisito; mientras exista voluntad para mejorar la gestión las demás limitantes serán superadas.
Para ello se requieren de ajustes tanto a nivel administrativo como jurídico que permitan la modernización del sector municipal. El ciudadano costarricense merece un trato adecuado y una buena calidad en los servicios públicos que recibe de su gobierno local por lo que el ente municipal esta obligada a realizar los ajustes que sean necesarios para brindarle el servicio en los términos que éste se merece.

\section{Referencias bibliográficas}

Aguilar, L. (2007). El aporte de la Política Pública y de la Nueva Gestión Pública a la gobernanza. Revista del CLAD Reforma y Democracia. No. 39, 1-15.

Asamblea Legislativa. (1998). Ley $N^{\circ} 7794$ denominada Código Municipal. San José, Costa Rica: Sistema Costarricense de Información Jurídica.

Contraloría General de la República . (2016). Memoria Anual 2015. San José, Costa Rica: Contraloría General de la República .

Contraloría General de la República. (2015). Informe DFOE-DL-IF-00004-2015 denominado Resultados del Índice de Gestión Municipal del periodo 2014. San José, Costa Rica : Contraloría General de la República.

Contraloría General de la República. (2016). Presupuestos públicos 2016 Situación $y$ perspectivas. Costa Rica : Contraloría General de la República.

Crozier, M., \& Friedberg, E. (1990). El actor y el sistema: Las restricciones de la acción colectiva. México: FCE.

Crozier, M. (s.f.). Estudio sobre el Poder y las estrategias de los Agentes. Fundación de Altos Estudios en Ciencias Económicas.

Espinosa Vizcaíno, F. (2011). Diseño y construcción de "Organizaciones Inteligentes". 
Friedmann, R. (2003). La gestión pública en el Siglo $X X I$. Anticipando los cambios que vienen Hacia un Sector Público Inteligente y en Constante Aprendizaje. Chile: Universidad Central.

Gandarillas, B., \& Briñol , P. (2010). El Cambio de Actitudes hacia Uno Mismo en el Contexto Organizacional: El Efecto del Formato de Pensamiento. Revista de Psicología del Trabajo y de las Organizaciones, 19-34.

García Sánchez, I. M. (2007). La nueva gestión pública: evolución y tendencias . España: Universidad de Salamanca.

Henric-Coll, M. (2014). La organización fractual: El futuro del management. Fractal Teams.

Jinesta Lobo, E. (2009). Tratado de Derecho Administrativo. San José, Costa Rica: Ius consultec s.a. Editorial Jurídica Continental.

Jinesta, E. (2002). Tratado de Derecho Administrativo. San José, Costa Rica: Editorial Diké.

Kliksberg, B. (s.f.). Una nueva gerencia pública para la modernización de Estado y afrontar los desafios de la integración. Director del Proyecto Regional de las Naciones Unidas para la Modernización del Estado (PNUD-CLAD).

Maxwell, J. (1999). Las 21 cualidades indispensables de un Líder. Estados Unidos: Grupo Nelson. Obtenido de http://habilidadesliderazgo. wikispaces.com

Mayorga, F., \& Córdova, E. (2007). Gobernabilidad y Gobernanza en América Latina. Ginebra.

Michel Crozier y la teoría de las organizaciones. (s.f.). Énfoques teóricos para el análisis político.

Mintzberg, H. (1991). Diseño de Organizaciones Eficientes. Buenos Aires: El Ateneo.
OCDE. (2012). Estudios de la OCDE sobre Gobernanza Pública: España de la reforma administrativa a la mejora continua. España: OCDEpublishing.

Pedraja, L., \& Rodríguez, E. (2004). Efectos del estido de liderazgo sobre la eficacia de las organizaciones públicas . Revista Facultad de Ingeniería, U.T.A.

Peña, V. (2011). El gobierno a través de las organizaciones y políticas públicas. Encrucijada: Revista Electrónica del Centro de Estudios en Administración Pública, $1-13$.

Peris Pichastor,R.(1998).Elliderazgoorganizacional: Un acercamiento desde las teorías implícitas. España: Tesis para alcanzar el grado de doctor en Administración.

Ramírez Amador, E. (2005). El cambio de paradigmas organizaciones. Revista Centroamericana de Administración Pública del ICAP $N^{\circ}$ 44-45.

Ramírez Amador, E. (2013). La caórdica y las organizaciones inteligentes. Revista Investiga.

Ramírez Amador, E. (febrero de 2016). Doctorado en Gestión Pública y Ciencias Empresariales. Material de lectura suministrado para el curso Diseño de las Organizaciones $y$ liderazgo. Costa Rica: Instituto Centroamericano de Administración Pública (ICAP).

Ramírez Guerra, C. (1999). Modelo de las configuraciones de Henry Mintzberg. Curso: Organización y métodos. Santiago, Chile: Escuela de Gobierno, Gestión Pública y Ciencia Política.

Rico, R., \& Fernández Rios, M. (2002). Diseño de organizaciones como proceso simbólico. Psicotherma.

Schvarstein , L. (1998). Diseño de Organizaciones : Tensiones y paradojas. Buenos Aires: Paidos Iberica. 